\title{
An experiment of the combined treatment of traditional Lei-huo-jiu therapy with Chinese medicine for the lacrimal gland of Sjögren's syndrome
}

\author{
Ming Jin • Haijiao Song • Lin Pan \\ Received: 12 February 2009 / Accepted: 17 June 2009 /Published online: 21 July 2009 \\ (C) The Author(s) 2009. This article is published with open access at Springerlink.com
}

\begin{abstract}
This experiment chooses nonobese diabetic (NOD) mouse as the animal model of Sjögren's syndrome and investigates the morphologic changes, the expression of inflammatory factors and growth factors of this mouse's lacrimal gland in response to a combined treatment of traditional Lei-huo-jiu therapy alone and in combination with Chinese medicine. The methods were to (1) use a morphological approach to directly observe pathological changes of the lacrimal gland in response to combined treatment and (2) to detect the level of tumor necrosis factor (TNF)- $\alpha$, interleukin (IL)-1, and nuclear factor kappa B (NF-KB) in lacrimal gland tissue caused by the combined treatments using a immunohistochemical approach. There is a reduction of the mast cell's degranulation and modulation of the level of cytokines in TNF- $\alpha$, IL-1, and NF-KB in the combined therapy group. The combined treatment of traditional Lei-huo-jiu therapy with Chinese medicine can improve the pathological changes of the lacrimal gland tissue of the NOD mouse through modulating the level of TNF- $\alpha$, IL-1, and NF-KB which results in improved tear secretion and function of the lacrimal gland.
\end{abstract}

Keywords Sjögren's syndrome · Lacrimal gland ·

Lei-huo-jiu $\cdot$ Nonobese diabetic (NOD) mouse

M. Jin $(\bowtie) \cdot H$. Song

Ophthalmology Department, China-Japan Friendship Hospital,

P.O. Box 100029, Beijing, China

e-mail: jinming321@yahoo.com.cn

L. Pan

Clinical Research Institute, China-Japan Friendship Hospital,

P.O. Box 100029, Beijing, China

\section{Introduction}

Sjögren's syndrome (SS) is a tear deficiency which includes both primary and secondary dry eye. Primary dry eye has the main symptom of dryness of the mouth and eye, while secondary dry eye is caused by autoimmune phenomena. Epidemiology indicates that the rate of dry eye is $0.5 \%$ and $3-5 \%$ following the San Diego Standard [1] and the Europe Standard [2], respectively. The main pathological course of SS is leukocytic infiltration of the lacrimal and salivary glands, which release a series of cytokines leading to the inflammation and destruction of glandular tissues, with resultant tear and salivary deficiency. The etiological agent for SS is not known. Many studies have investigated the protein content of tears of Sjögren's syndrome patients, which includes the autoimmune cytokines, inflammational cytokines, growth factors, and so on.

While the treatment for SS has been limited to topical lubricants and cyclosporine, traditional Chinese medicine (TCM) may hold promise as a complementary measure to existing therapy. Our clinical observations have indicated that using Lei-huo-jiu in a moxibustion technique to infiltrate the area around both eyes of SS has yielded positive effects. To test our clinical observation, this experiment investigates the mechanisms of the combined treatment of traditional Lei-huo-jiu therapy alone and in combination with Chinese herbal medicines using a murine model for SS. To test the response to treatment, we will examine the lacrimal gland's secretory capacity by morphological methods and will measure inflammatory cytokines and growth factors in lacrimal gland tissue using an immunohistochemical approach. 


\section{Materials and methods}

Experiment materials

Animal model selection There were thirty female nonobese diabetic (NOD) mice with SPF grade, aged 5 weeks old, and body weight 17.0 20.2 $\mathrm{g}$ and ten female KunMing mouse with SPF grade and aged 5 weeks old. Mice were provided by Chinese Academy of Medical Sciences.

Experimental Chinese medicines (1) Zhao shi Lei-huo-jiu, ChongQing Zhao Shi Lei-huo-jiu was provided by the Traditional Medicine Institute and (2) Chinese medicine (Yang Yin Sheng Jin fang) was from Hong shen, Mai dong, Tian hua fen, Wu wei zi, Bo he, and so on.

Main reagents These are $4 \%$ paraformaldehyde, Bouin solution, bitter acid, gradient alcohol (70-100\%), xylene, hematoxylin-eosin stain, acetone, tumor necrosis factor (TNF) antibody, interleukin (IL)-1antibody, nuclear factor kappa B (NF-KB) antibody, ChemMateTMEnVision+/HRP immunohistochemistry kit (DAKO Co.), and DAB developer (DAKO Co.).

Custom-designed smoking box for mice undergoing Lei-huo-jiu therapy This box was $70 \times 40 \times 50 \mathrm{~cm}^{3}$, transparent top with six round air holes (each $1 \mathrm{~cm}^{2}$ ) convenient to observe the animal's condition in box during treatment, and one treatment hole (diameter $4 \mathrm{~cm}$ ) on each side for the Lei-huo-jiu stick.

\section{Groups}

NOD rats, whose exocrine glands demonstrate groups lymphocytic infiltration, have been certified as the ideal animal model of SS.

1. Control group: ten KunMing mice

2. Model group: ten NOD mice

3. Lei-huo-jiu therapy group: ten NOD mice

4. The combined therapy of Lei-huo-jiu therapy and Chinese medicine group: ten NOD mice

\section{Methods}

Administration methods Neither the control group nor the model group underwent treatment. In Lei-huo-jiu therapy group, Lei-huo-jiu treatment was $20 \mathrm{~min}$ and bid for 4 weeks. In the combined therapy group, Lei-huo-jiu treatment was $20 \mathrm{~min}$ and bid, plus Chinese herbal medicinal broth with intragastric administration and bid. The dose is calculated according to body weight of the mouse. Duration of treatment is 4 weeks.
Lei-huo-jiu therapy Place the two treatment groups of mice into a smoking box and light two Lei-huo-jiu sticks, then insert them into the box through the side holes. Sticks were kept lit throughout $30 \mathrm{~min}$ of treatment. Mice were observed during treatment to ensure normal activity during smoking treatment session.

Specimen and stain Mice were executed and both lacrimal glands were fixed in $4 \%$ formalin solution for $24 \mathrm{~h}$, then placed into gradient alcohol for dehydration, and finally embedded into paraffin and cut into $3-\mu \mathrm{m}$ sections and stained with hematoxylin and eosin.

Morphological observation Morphological changes of the mice's lacrimal tissues were observed using an optical microscope.

Immunohistochemical detection Once dewaxed, paraffin sections are put into $0.3 \% \mathrm{H}_{2} \mathrm{O}_{2}$ solution for blocking endogenous peroxidase, specimens were then douched with lotic water, then into phosphate-buffered saline (PBS) for $5 \mathrm{~min}$, and this was repeated three times before placing into the humid box. Dilute the TNF antibody (1:100), IL-1 antibody (1:50), and NF-KB antibody (1:100) with antibody dilution as first antibody, dropwise apply $50 \mu \mathrm{L}$ of first antibody fluid onto each section, and $4{ }^{\circ} \mathrm{C}$ refrigerate for $24 \mathrm{~h}$, laying negative control at the same time. Dropwise apply $50 \mu \mathrm{L}$ of second antibody fluid onto each section after $24 \mathrm{~h}$, incubate for $1.5 \mathrm{~h}$ at room temperature, then place into PBS buffer, soak for $5 \mathrm{~min}$, and repeat three times, followed by coloration, dehydration, transparence, and mounting.

Outcome analysis Picking the upper, middle, and lower three optical fields, we took photographs in bright field for the immunohistochemical specimens using a light microscope.

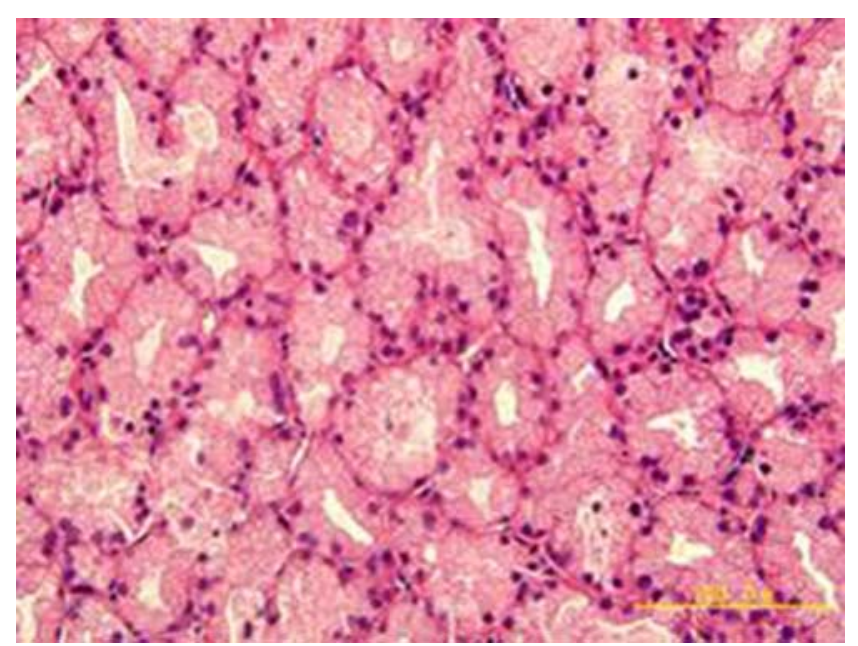

Fig. 1 Nomal Kun Ming mice's lacrimal gland tissue, HE $\times 400$ 


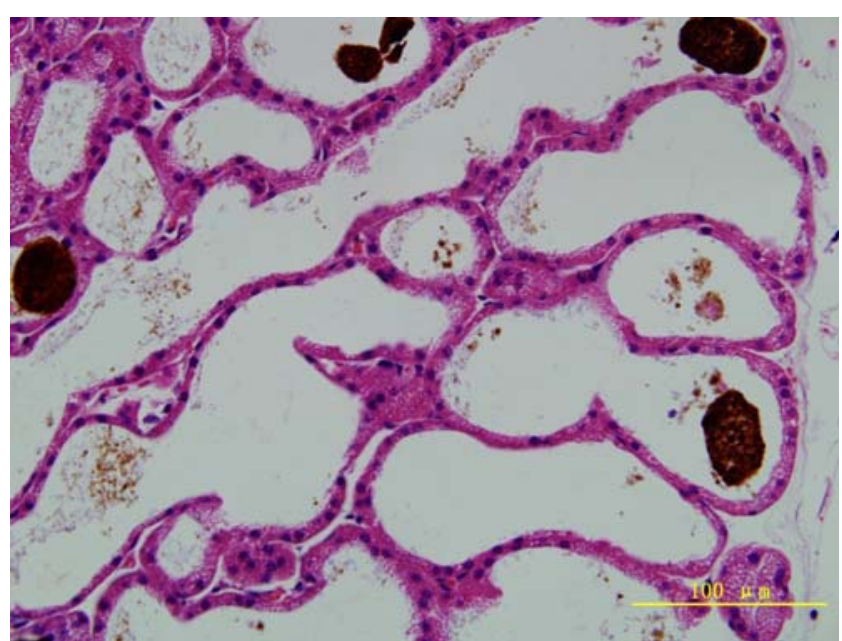

Fig. 2 In model group, endothecium secretory cells of gland alveoluses flatten and the acinar lumina expand. Some cavities are full of deep-brown globular structures, HE $\times 400$

Image analysis Measure the immunohistochemical staining intensity by using the Image Plus Pro image analysis system and undertake quantitative analysis. Calculate the integrated optical density (IOD): IOD $=$ area $\times$ density.

Statistic analysis Use SPSS software for statistical analysis.

\section{Result}

Light microscopic observation

Lacrimal gland tissue in control group Lacrimal gland tissue consists of glandular acini, which are round or

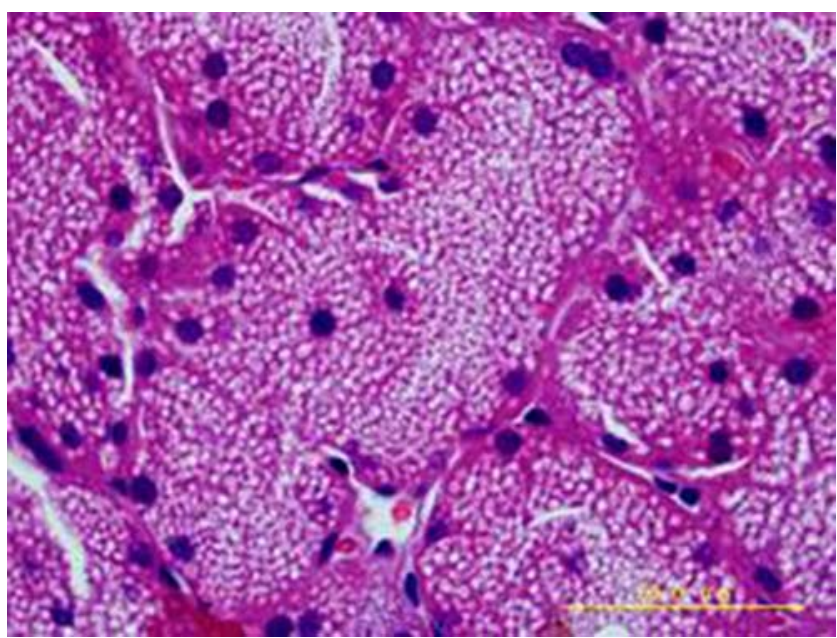

Fig. 3 In model group, some endothecium secretory cells of gland alveoluses accumulate great of secretory granules, so the acinar lumina disappear or collapse, $\mathrm{HE} \times 1,000$

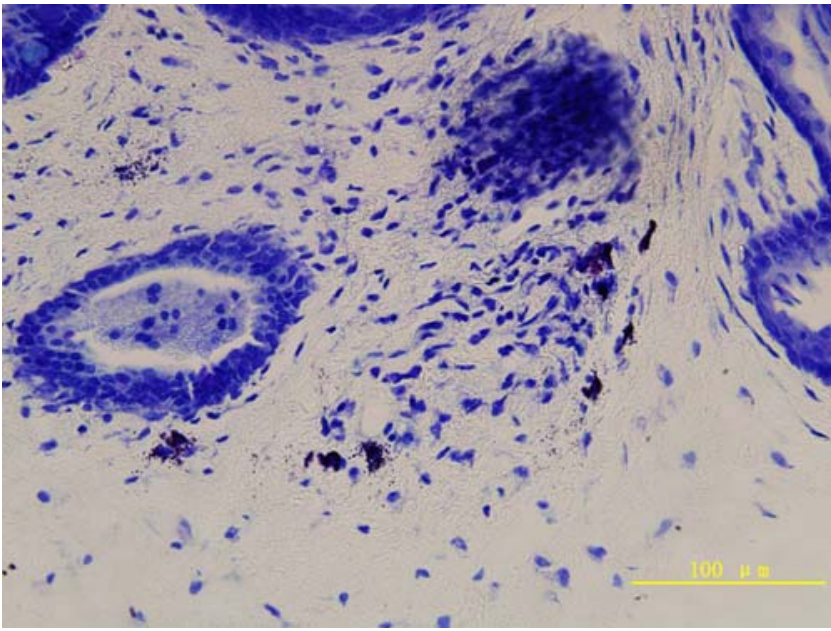

Fig. 4 In model group, grain-doff mast cells are observed in connective tissue surrounding the lacrimal gland tissue, toluidine blue stain $\times 400$

irregular cellular islands, with a central air space. Surrounding glandular acini are endothelial secretory cells which are lined up in order, with an intermittent arrangement of myoepithelial cells. Acini of the lacrimal gland are grouped in lobules which are separated by fibrous tissue (Fig. 1).

Lacrimal gland tissue in model group Endothelial secretory cells of the acini line up in a disorderly fashion, and their secretory granules are lost, so the cells flatten and the acinar lumina expand (Fig. 2). While some endothelial secretory cells accumulate great number of secretory granules, the acinar lumina disappear or collapse (Fig. 3). Some cavities are full of deep brown globular structures. To add to the abnormal appearance, grain-doff mast cells are observed in the connective tissue surrounding the lacrimal gland tissue (Fig. 4).

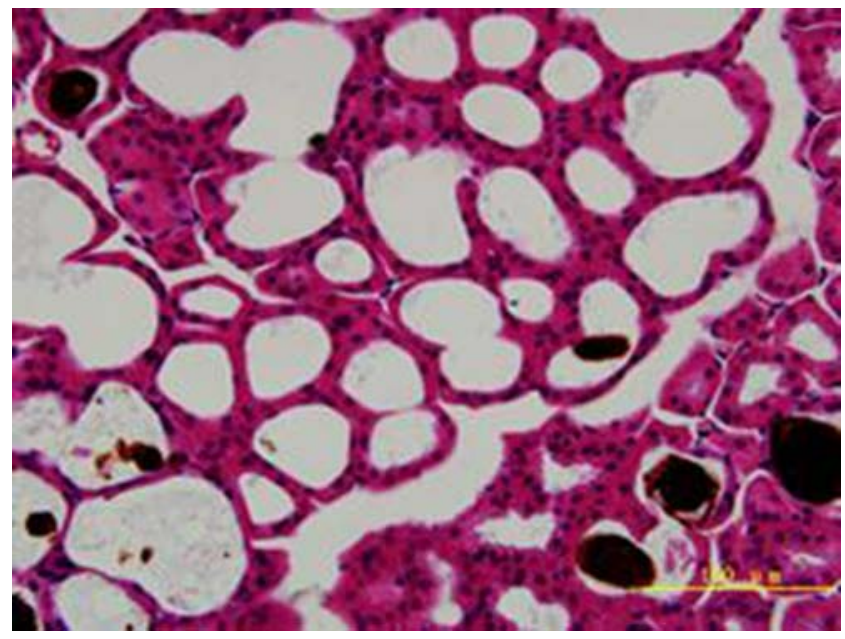

Fig. 5 The lacrimal gland tissue's pathological changes in the combined therapy group, $\mathrm{HE} \times 400$ 


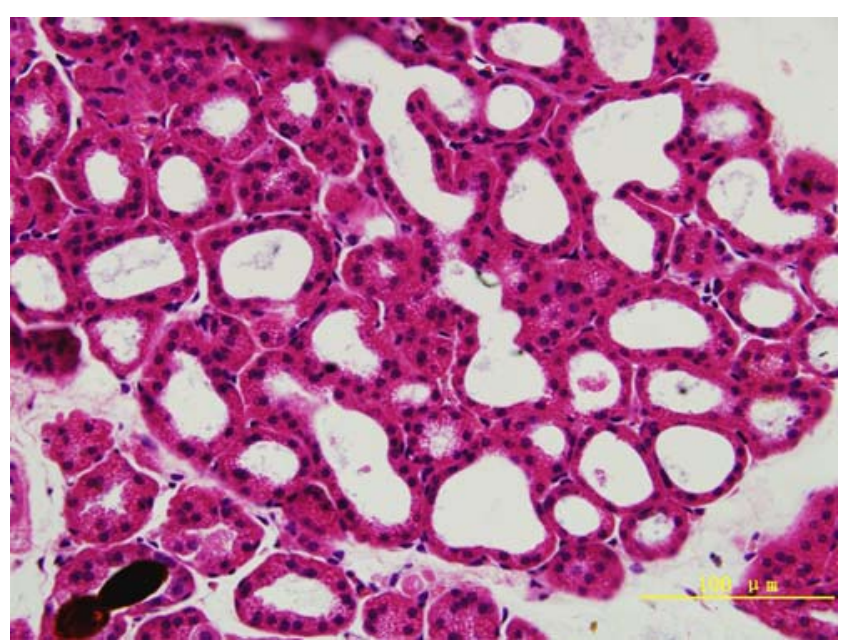

Fig. 6 The lacrimal gland tissue's pathological changes in Lei-huo-jiu therapy group, $\mathrm{HE} \times 400$

Lacrimal gland tissue in treated group Compared with the model group, pathological changes of the lacrimal gland tissue are less pronounced in the combined therapy group. There is less disorder of the endothelial secretory cells of the acini, with less distention or collapsed of acinar lumina (Figs. 5 and 6). Pathological changes of lacrimal gland tissue in Lei-huo-jiu therapy group is slightly improved when compared with the combined therapy group.

Expression of three inflammatory factors in lacrimal gland tissue

\section{Expression of TNF- $\alpha$ in lacrimal tissue}

TNF- $\alpha$ is present in the interstitium surrounding acinous cells in control group, showing up buff (Fig. 7). In the model

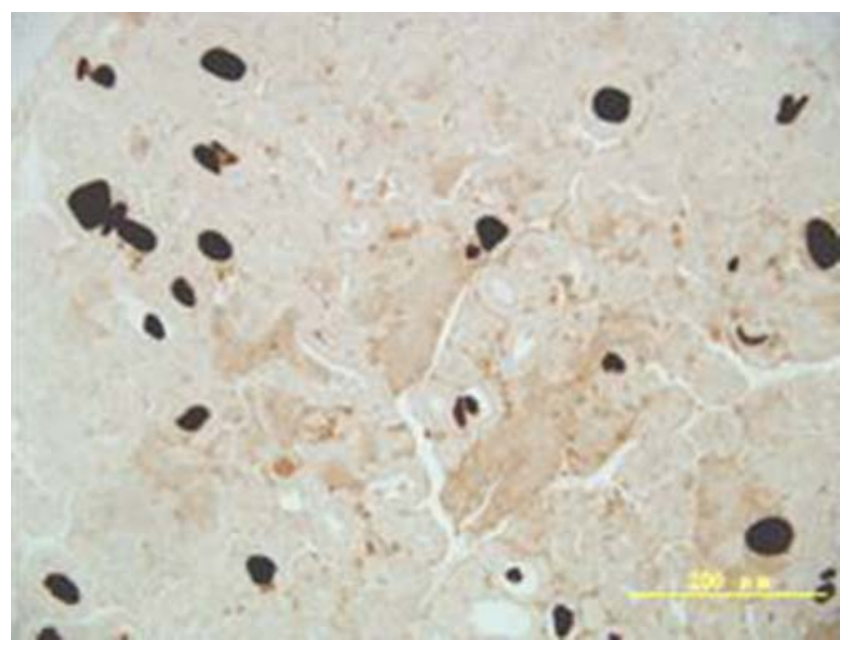

Fig. $7 \mathrm{TNF}-\alpha$ is observed to depress in interstitium surrounding acinous cells in control group, showing up buff, $\times 200$

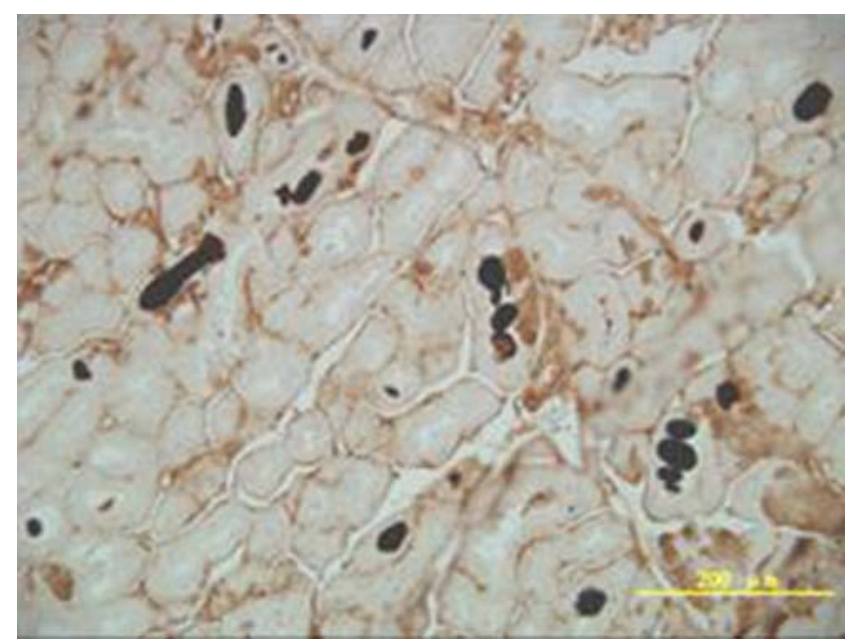

Fig. 8 In model group TNF- $\alpha$ is observed to depress more, showing up buff, $\times 200$

group, there is greater expression of TNF- $\alpha$, with both area and stain intensity increased compared to that of the control group (Fig. 8). In both treatment groups, TNF- $\alpha$ is observed to less than in the model group, with a comparatively reduced area and stain intensity (Figs. 9 and 10).

\section{Expression of IL-1 in lacrimal tissue}

IL-1 is present in the interstitium surrounding acinous cells in the control group, showing up buff (Fig. 11). In the model group, there is relatively increased expression, with both area and stain intensity greater than that seen in the control group (Fig. 12). In the combined therapy group, IL-1 is present to a lesser degree than in model group, both in area and stain intensity (Fig. 13), while in Lei-huo-jiu alone treatment group, there is no apparent difference compared to the model group (Fig. 14).

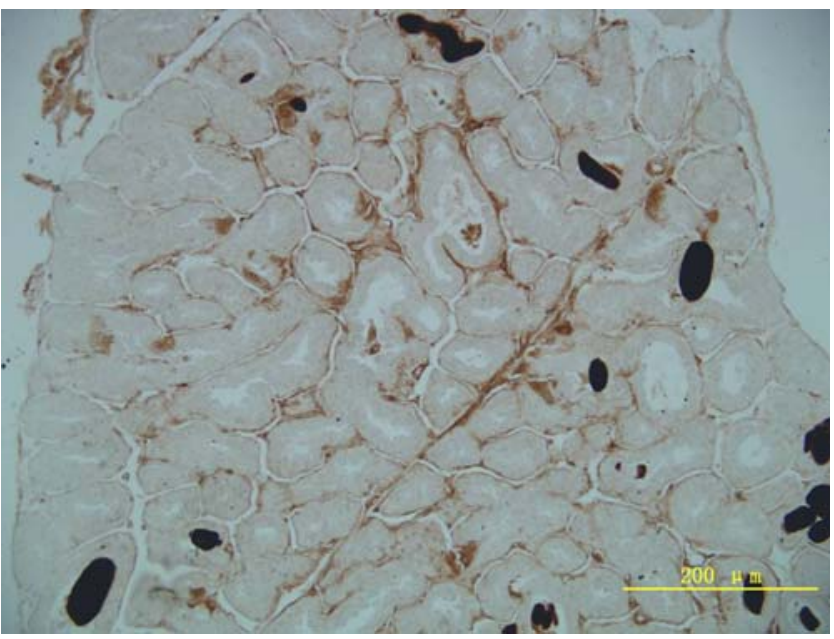

Fig. $9 \mathrm{TNF}-\alpha$ is observed to depress less in Lei-huo-jiu therapy group, $\times 200$ 


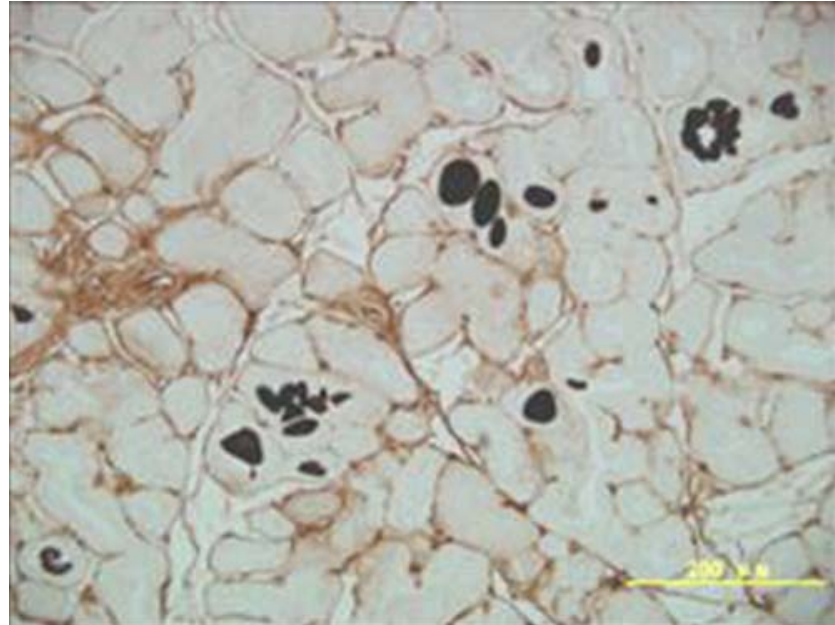

Fig. $10 \mathrm{TNF}-\alpha$ is observed to depress less in the combined therapy group, $\times 200$

\section{Expression of $N F-\kappa B$ in lacrimal tissue}

$\mathrm{NF}-\mathrm{KB}$ is present in the interstitium surrounding acinous cells in the control group, showing up buff (Fig. 15). In the model group, there is relatively increase expression, both area and stain intensity greater than that seen in the control group (Fig. 16). In both treatment groups, NF- $\mathrm{KB}$ is reduced compared to the model group, both in area and stain intensity (Figs. 17 and 18).

\section{Computer image analysis}

Compared with the control group, the IODs of TNF- $\alpha$, IL-1, and NF-kB are larger in model group $(P<0.05$ and $P<0.01$, respectively). Compared with the model group, the IOD

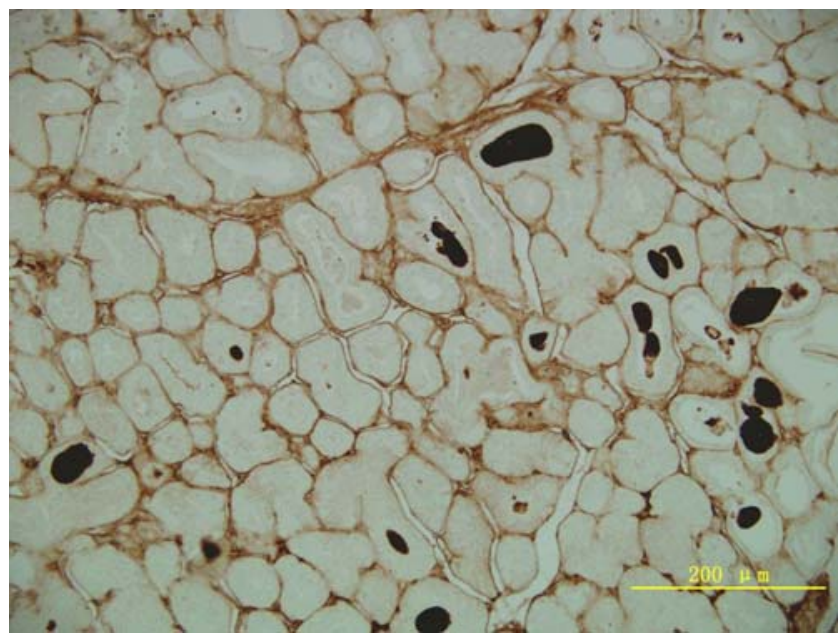

Fig. 11 IL-1 is observed to depress in interstitium surrounding acinous cells in control group, showing up buff, $\times 200$

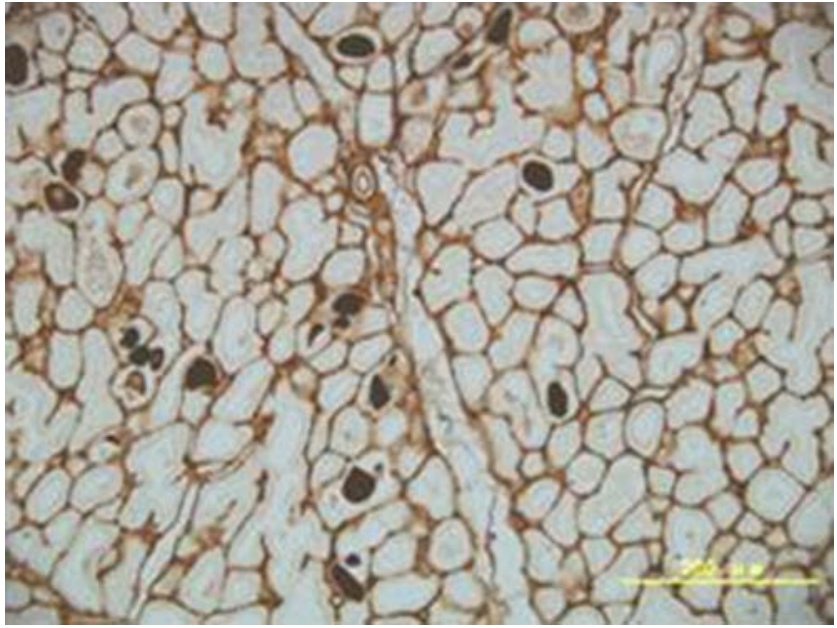

Fig. 12 In model group, IL-1 is observed to depress more, showing up buff, $\times 200$

of all three cytokines is lower in the combined therapy group $(P<0.05)$, and the IOD of TNF- $\alpha$ and NF-KB, but not IL-1, is lower in the Lei-huo-jiu therapy group $(P<0.05)$. Table 1

\section{Discussion}

Animal model

SS is an autoimmune disease with lymphocytic infiltration of the exocrine glands as a distinct pathologic feature of the disease. NOD mice, whose exocrine glands show lymphocytic infiltration, have been generally accepted as an ideal animal model for SS. Researches of NOD mice have shown

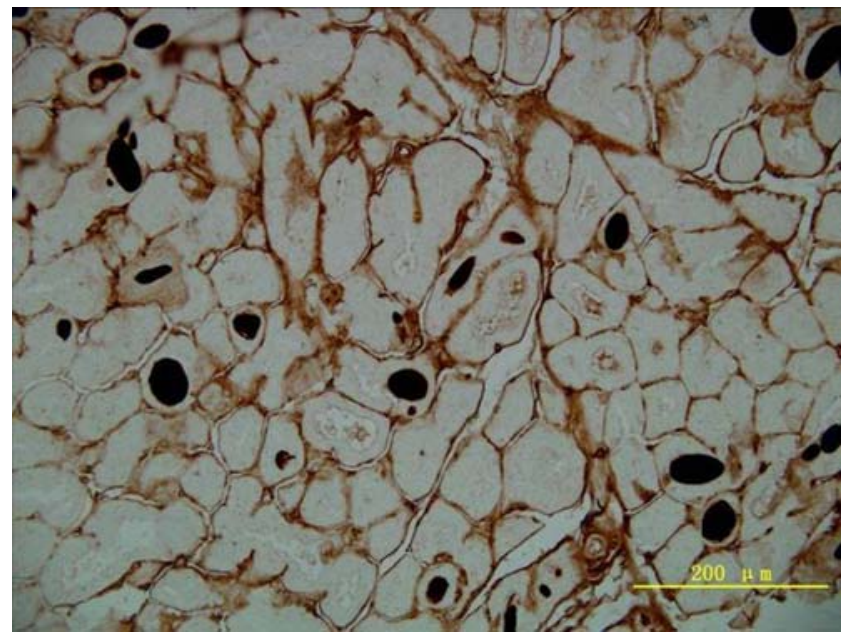

Fig. 13 In Lei-huo-jiu therapy group, no difference was observed as compared with the model group, $\times 200$ 


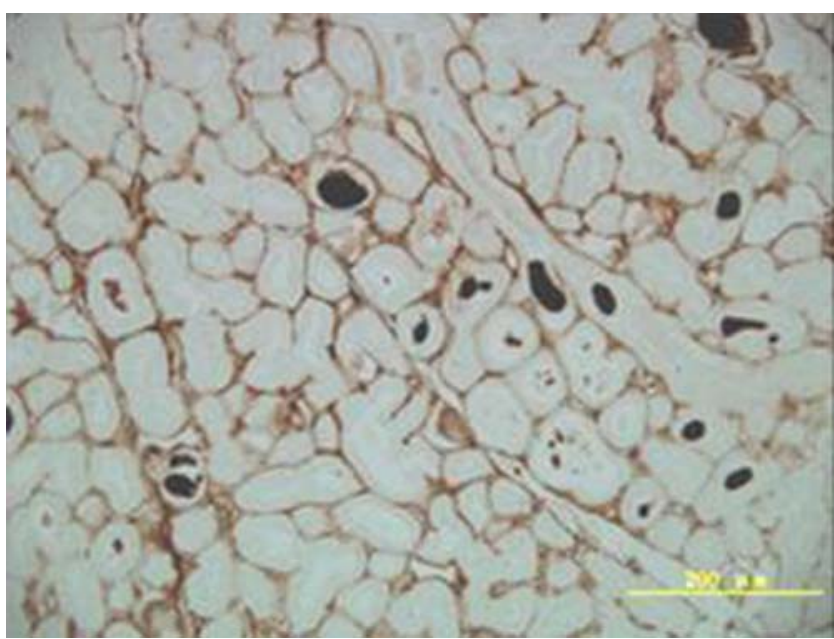

Fig. 14 IL-1 is observed to depress less in the combined therapy group, $\times 200$

that lymphocytic infiltration is observed in the pancreas, lacrimal gland, submaxillary gland, and other organs of these animals [3]. Humphreys Beher [4] confirmed that for NOD mice, the lacrimal gland's function is reduced. We have observed pathological changes in 5-week-old NOD mice, when infiltration of inflammatory cells begins to appear in their lacrimal glands. This inflammation in lacrimal gland is consistent with the distinctive pathological change of SS.

When compared with control group, the lacrimal gland of the untreated NOD model group has several differences: (1) There are groups of infiltrating inflammatory cells. (2) Endothelial secretory cells of glandular acini line up in an obviously disorderly manner and their secretory granules are lost, so that the cells flatten and the acinar lumina appear to be distended (Fig. 2). (3) Other endothelial

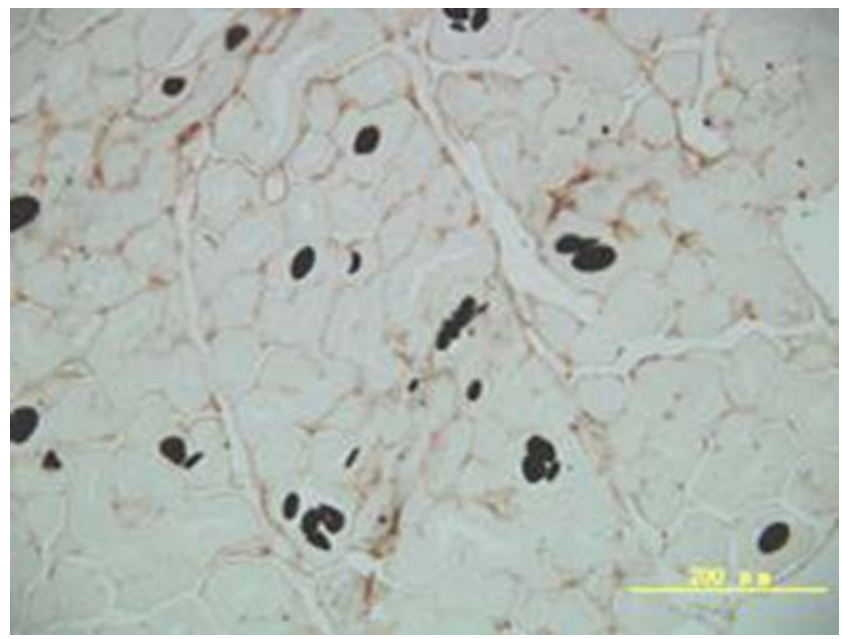

Fig. 15 NF- $\mathrm{kB}$ is observed to depress in interstitium surrounding acinous cells in control group, showing up buff, $\times 200$

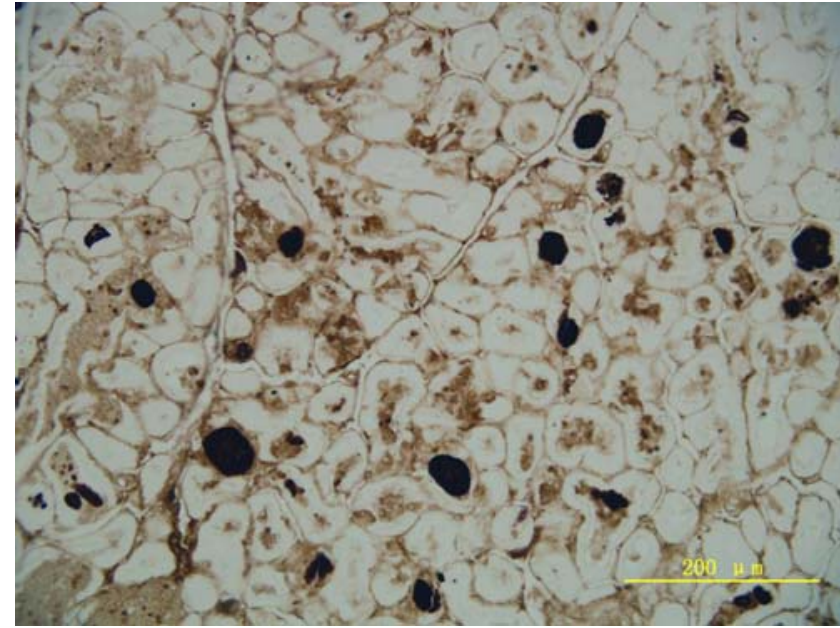

Fig. 16 In model group, NF- $\mathrm{kB}$ is observed to depress more, showing up buff, $\times 200$

secretory cells accumulate a great number of secretory granules, to the degree that the acinar lumina disappear or collapse (Fig. 3). This indicates that those secretory granules are difficult to discard, and such inspissation of these granules may aggravate local inflammation. Some cavities are full of deep brown globular structures. (5) Grain-doff mast cells are observed in connective tissue surrounding the lacrimal gland tissues (Fig. 4).

Activated mast cells produce remarkable effects which include the infiltration of lymphocytes to participate in the release of various mediators and cytokines [5]. Since graindoff mast cells cannot be found in the control group, we speculate that some of the inflammatory cytokines may arise from the grain-doff mast cells, but this requires confirmation. These three morphological changes which we have observed in the NOD mouse's lacrimal gland are

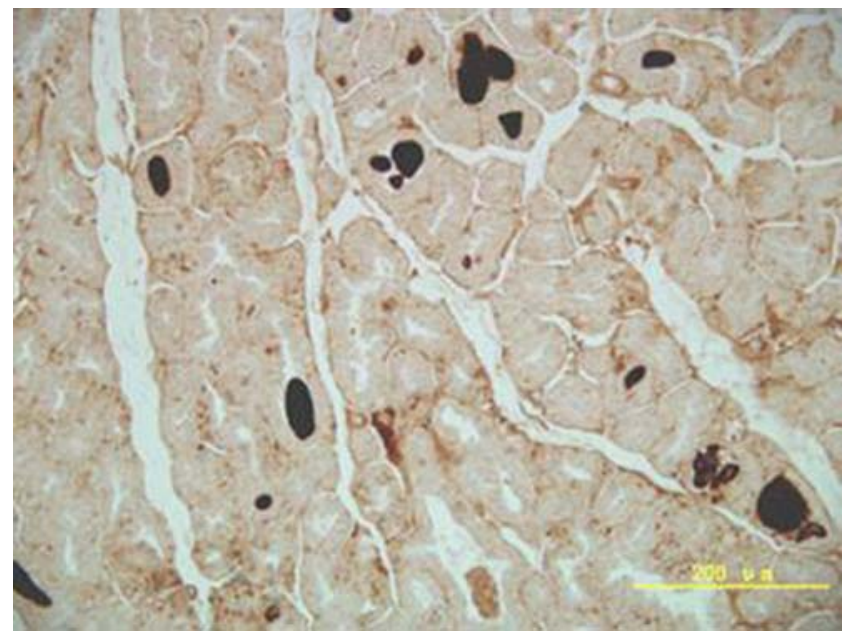

Fig. 17 NF- $k B$ is observed to depress less in Lei-huo-jiu therapy group, $\times 200$ 


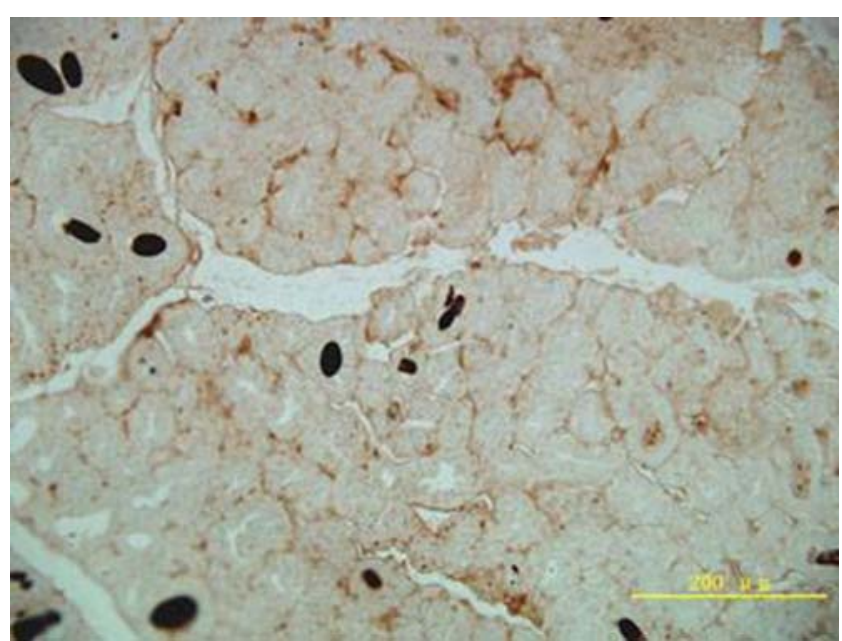

Fig. $18 \mathrm{NF}-\mathrm{KB}$ is observed to depress less in the combined therapy group, $\times 200$

in keeping with early pathological changes of SS in other related research [6-13], so it is here further supported as an ideal animal model of SS.

The traditional therapy for the NOD mouse's lacrimal gland

In TCM terms, "Zhao Shi Lei-huo-jiu" is a moxibustion treatment that delivers Chinese herbs in a strong smoke which is thought to adjust the QI-blood of an organism's meridians. This effect is very similar to acupuncture. Related empirical study has confirmed that it can advance local blood circulation rapidly and promote topical metabolism and function. According to TCM theory, we chose Hong shen, Mai dong, Wu weizi, Tian huafen, and Bo he to compose our formula. In the formula, Hong shen benefits vital energy and promotes the production of body fluid; Mai dong, Wu weizi nourishes yin; Tian huafen removes heat to promote salivation; and Bo he is cool.

After 4 weeks of treatment, the results show that (1) in both the Lei-huo-jiu therapy group and the combined therapy group, pathological changes of NOD mice's lacrimal gland are improved compared with the model group; (2) deep brown globular structures are observed in all the NOD mice groups, while in Lei-huo-jiu therapy and the combined therapy groups, this phenomenon is reduced; and (3) grain-doff mast cells are observed in connective tissue surrounding the lacrimal gland tissue in all the untreated NOD mice, while in the two treated groups, there is a reduction of the population of grain-doff mast cells. We presume that the curative effect following traditional treatments is that they may reduce local inflammation and promote the lacrimal gland's secretory function.

The traditional therapy for NOD mice's inflammational cytokines in lacrimal gland

Some researches indicated that there is an elevated level of TNF and IL-1 in SS patients' blood, and the level of these two cytokines is related to pathological grading. Researchers consider that these two cytokines play an important role in autoimmune diseases. In the clinical setting, it is difficult to harvest the lacrimal gland. Thus, research to investigate inflammatory cytokines in lacrimal tissue has been rarely conducted.

We detected levels of TNF- $\alpha$, IL-1, and NF- $\mathrm{BB}$ in lacrimal gland tissue using an immunohistochemical approach. The results show that the levels of TNF- $\alpha$, IL-1, and NF- $\mathrm{KB}$ are higher in model group when compared to the control group. On the other hand, when compared with the model group, the levels of all these three cytokines are lower in the combined therapy group. Levels of TNF- $\alpha$ and $\mathrm{NF}-\kappa \mathrm{B}$ were lower in the Lei-huo-jiu therapy alone group, but the level of IL-1 was not decreased as it was in the combined therapy group. To some degree, the addition of the Chinese herbal therapy in the gastric lavage potentiated the therapy to reduce all three inflammatory cytokines in lacrimal gland. It appears that inflammatory mechanisms are at play, and therapy to reduce these inflammatory cytokines can improve the pathological changes of the lacrimal gland of NOD mice. Further studies are needed to understand the relatively higher levels of NF-KB in relation

Table 1 Computer image analysis for IOD of three inflammatory cytokines (IOD $=$ area $\times$ density)

\begin{tabular}{llll}
\hline Group & TNF- $\alpha$ (IOD) & IL-1 (IOD) & NF-kB (IOD) \\
\hline Control group & $206,811.8 \pm 333.87$ & $1,861,260 \pm 371.32$ & $1,949,437 \pm 426.72$ \\
Model group & $1,813,602 \pm 200.92^{* *}$ & $2,325,086 \pm 510.41^{*}$ & $2,411,554 \pm 355.95^{*}$ \\
Lei-huo-jiu therapy group & $1,449,907 \pm 518.56^{* * *}$ & $2,412,896 \pm 421.73$ & $1,894,509 \pm 392.81^{* * *}$ \\
Combined therapy group & $1,478,449 \pm 232.39^{* * * *}$ & $1,949,694 \pm 316.44^{* * * *}$ & $2,165,945 \pm 386.39 * * * *$ \\
\hline
\end{tabular}

$* P<0.05$ (model group is significantly different as compared with control group); ${ }^{* *} P<0.01$ (model group is significantly different as compared with control group); $* * * P<0.05$ (Lei-huo-jiu therapy group is observed to be different as compared with model group); $* * * * P<0.05$ (the combined therapy group is significantly different as compared with model group) 
to the elevated levels of the other inflammatory cytokines in the model group and what role it may play in pathogenesis of SS.

\section{Conclusion}

Lei-huo-jiu therapy alone and combined therapy can modulate the level of inflammatory markers in lacrimal gland in an animal model of Sjögren's syndrome. We speculate that inflammatory mechanisms may be at play in the pathological changes of lacrimal tissues since these changes improve with treatment. Further studies are needed to confirm this pathophysiological mechanism of disease.

Open Access This article is distributed under the terms of the Creative Commons Attribution Noncommercial License which permits any noncommercial use, distribution, and reproduction in any medium, provided the original author(s) and source are credited.

\section{References}

1. Nava A, Barton K, Monroy DC, Pflugelder SC. The effects of age, gender, and fluid dynamics on the concentration of tear film epidermal growth factor. Cornea. 1997;16:430-8.
2. Frost-Larsen K, Isager H, Manthorpe R, Prause JU. Sjögren's syndrome. Ann Ophthalmol. 1980;12:836-46.

3. Chen H, Li Z. A review of animal model for Sjögren's syndrome. Chin J Rheumatol. 2004;8(8):493-6.

4. Humphreys Beher MG, Hu Y, Nakagawa Y, et al. Utilization of the non-obese diabetic mouse as an animal model for the study of secondary Sjögren's syndrome. Adv Exp Med Biol. 1994;350:631-6.

5. Deng W, Li P. Advancement in research of mast cell. Chinese Journal of Medical Laboratory Technology. 2003;4(3):158-160.

6. Kong L, Fei P, Gong Y, et al. Pathology research for lacrimal gland tissue in Sjögren's syndrome. Chin J Ophthalmol. 1994;11 (30):6434-5.

7. Wang S, Bruce B, Di S. Functional, sialographic and pathological changes in salivary glands of autoimmune disease-prone nonobese diabetic mice. Beijing J Stomatol. 2002;10(2):55-7.

8. Guo Q, Gu Y. M3 receptors antibody and exocrine gland's damaged function and treatment for Sjögren's syndrome. Chin J Rheumatol. 2002;6(3):198-200.

9. Liu N, Zeng H, Qi D, et al. Presence of apoptosis and expression of Fas antigen in sialaden of Sjögren's syndrome. J Modern Stomatol. 1998;4(12):268-70.

10. Li X, Gan X. Detection of 3 cytokines in labial gland tissue of Sjögren's syndrome patients. Chin J Rheumatol. 1999;9(3):314850.

11. Guo Z, Wang Z, Zhang X. Detection of the level of TNF in Sjögren's syndrome patients. Chin J Misdiagnostics. 2002;4 (2):4570-1.

12. Solomon A, Dursun D, Liu Z, et al. Pro-and anti-inflammatory forms of interleukin-1 in the tear fluid and conjunctiva of patients with dry eye disease. Invest Ophthalmol Vis Sci. 2001;42:228392.

13. Luo J, Jin F. Nuclear factor- $\kappa B$ and immune response. Foreign Medical Sciences Immunology. 2004;27(5):294-7. 